\title{
Might CPAP prevent exacerbation in patients with COVID-19 with or without obstructive sleep apnea?
}

\section{Kazuo Chin ${ }^{1}$}

Published online: 2 January 2021

(c) Japanese Society of Sleep Research 2021

The Department of Respiratory Care and Sleep Control Medicine is funded by endowments from Philips, ResMed, Fukuda Denshi, and Fukuda Lifetec Keiji to Kyoto University. He has also received honoraria for giving lectures from Philips, and Teijin Pharma.

Coronavirus disease 2019 (Covid-19) was first discovered in Wuhan, China in late 2019[1]. Thereafter there has been a rapid spread of the virus, leading to a global pandemic. Risk factors for severe COVID-19 were reported such as older age, chronic obstructive pulmonary disease, cardiovascular disease (e.g., heart failure, coronary artery disease, or cardiomyopathy), type 2 diabetes mellitus, obesity, sickle cell disease, chronic kidney disease, immunocompromised state from solid-organ transplantation, and cancer [2]. Many of these risk factors overlap with obstructive sleep apnea. The prevalence of patients with moderate to severe obstructive sleep apnea is high, especially among those with obesity and/or lifestyle-related diseases. Benjafield reported that 936 million adults aged 30-69 years had mild to severe OSA and 425 million had moderate to severe OSA [3]. In addition to that report, recent reports showed that more than $20 \%$ of middle-aged adult males and nearly $10 \%$ of post-menopausal females had moderate to severe OSA [4]. Therefore, it is important to evaluate COVID-19 management from the viewpoint of OSA because risk factors for OSA mimic the risk factors for COVID-19. But the number of manuscripts reporting the prevalence of OSA in patients with COVID19 is scant. The reported data on the prevalence of OSA in COVID-19 patients showed lower rates than in the general population. Richardson et al. reported 154 (2.9\%) OSA patients out of 5700 patients with COVID-19 [5] and Cade

Kazuo Chin

chink@kuhp.kyoto-u.ac.jp

1 Department of Respiratory Care and Sleep Control Medicine, Graduate School of Medicine, Kyoto University, Shogoin 54, Kawahara-cho, Sakyo-Ku, Kyoto 606-8507, Japan et al. reported 443 (9.5\%) out of 4668 COVID-19 patients. As to this issue [6], Sullivan, who was the inventor of nasal continuous positive airway pressure treatment (CPAP), stated that CPAP should be used not only in the management of patients with OSA but in managing COVID-19 patients with or without hypoxemia [7], although some recommended not to use CPAP. He proposed the hypothesis that unrecognized snoring and sleep apnea might be significant mechanisms increasing viral aspiration during sleep and that this may induce aspiration of COVID-19 virus, worsening pulmonary lesions, and inducing viral pneumonia, which might be prevented by CPAP [7]. Although this hypothesis is not fully proven, the use of well-fitted CPAP masks with appropriate circuit filters can minimize viral spread to others, including medical staff, and may lead to good management and improved prognosis for patients with COVID-19. We also should recognize that at present it has not been proven that such CPAP systems even if used in a negative pressure room are completely safe for medical staff. Considering these issues, it would be better for us to use a proper CPAP system under appropriate circumstances for COVID19 patients cautiously because the benefit of using CPAP for the management of COVID-19 patients would be superior to not using it with regard to patients' prognosis, as Sullivan proposed [7].

\section{References}

1. Zhu N, Zhang D, Wang W, Li X, Yang B, Song J, Zhao X, et al. A novel coronavirus from patients with pneumonia in China, 2019. N Engl J Med. 2020;382:727-33.

2. Gandhi RT, Lynch JB, Rio C. Mild or moderate Covid-19. N Engl J Med. 2020;383:1757-66.

3. Benjafield AV, Ayas NT, Eastwood PR, Heinzer R, Ip MSM, Morrell $\mathrm{MJ}$, et al. Estimation of the global prevalence and burden of obstructive sleep apnoea: a literature-based analysis. Lancet Respir Med. 2019;7:687-98.

4. Matsumoto T, Murase K, Tabara Y, Gozal D, Smith D, Murase K, et al. Impact of sleep characteristics and obesity on diabetes and 
hypertension across genders and menopausal status: the Nagahama study. Sleep. 2018;41(7):07. https://doi.org/10.1093/sleep/ zsy071.

5. Richardson S, Hirsch JS, Narasimhan M, Crawford JM, McGinn T, Davidson KW. Presenting characteristics, comorbidities, and outcomes among 5700 patients hospitalized with COVID-19 in the New York City Area. JAMA. 2020;323:2052-9.

6. Cade BE, Dashti HS, Hassan SM, Redline S, Karlson W. Sleep apnea and COVID-19 mortality and hospitalization. Am J Respir Crit Care Med. 2020;202:1462-4.
7. Sullivan CE. Snoring and obstructive sleep apnoea as risk factors in SARS-Cov-2: can nasal CPAP during sleep reduce pneumonia risk? https://doi.org/10.1007/s41105-020-00295-5.

Publisher's Note Springer Nature remains neutral with regard to jurisdictional claims in published maps and institutional affiliations. 